\title{
Freqüências de Corte e Intensidades de Desfolha em Duas Cultivares de Alfafa (Medicago sativa, L). 1. Peso, Número, Produção Estacional e Dinâmica de Aparecimento das Brotações Basilares
}

\author{
Alda Lúcia Gomes Monteiro', Moacyr Corsi², Dora Duarte de Carvalho3
}

\begin{abstract}
RESUMO - O experimento foi realizado em Piracicaba, SP, durante um ano, com duas cultivares de alfafa (Crioula e CUF-101), plantadas em vasos a céu aberto. O peso e o número de brotos basilares foram mensurados. Foram avaliados a dinâmica de sua rebrota após o corte e a estacionalidade de produção, por intermédio de três freqüências de corte, 28, 35 e 42 dias, e três intensidades de desfolha, e os cortes a $7 \mathrm{~cm}$ de altura com e sem preservação da área foliar remanescente e corte rente ao solo. Foi usado delineamento inteiramente casualizado em arranjo fatorial 2 × 3 x 3 (cultivar, freqüência de corte e intensidade de desfolha), com três repetições. Para a avaliação da produção estacional, nas três freqüências isoladamente, o delineamento experimental em parcelas subdivididas no tempo foi usado, em que as parcelas foram representadas pelos tratamentos (cultivar vs intensidade de desfolha) e as subparcelas, pelos cortes. A freqüência de corte de 28 dias foi a melhor para ambos as cultivares quanto à produção de matéria seca de brotos/vaso, principalmente no verão. Quanto ao número de brotações, as freqüências de corte de 28 e 35 dias foram superiores à freqüência de corte de 42 dias. A intensidade de desfolha a $7 \mathrm{~cm}$, com preservação da área foliar remanescente, foi superior às demais, quanto ao peso e número de brotos. O período de verão mostrou-se bastante favorável à produção destas cultivares de alfafa. Quanto ao aparecimento das brotações, mais de 2/3 dos brotos surgiram nas duas primeiras semanas após o corte, independente da freqüência do corte e da intensidade de desfolha. Em condições tropicais, existe possibilidade de obtenção de altos níveis de produção em plantas de alfafa, desde que seja adotado intervalo de cortes por volta de 28 dias. Além disso, cortes de aproximadamente $7 \mathrm{~cm}$ do solo são favoráveis, por explorarem a capacidade fotossintética da área foliar remanescente e das brotações já presentes no momento do corte.
\end{abstract}

Palavras-chave: alfafa, cv. Crioula, cv. CUF-101, manejo de cortes

\section{Cutting Frequencies and Defoliation Intensities on Two Alfalfa (Medicago sativa, L) Cultivars. 1. Weight, Number, Seasonal Production and Dynamic of Appearance of Basal Shoots}

\begin{abstract}
The experiment was carried out at Piracicaba, SP, over one year, with two alfalfa cultivars (Crioula and CUF-101) grown in pots at open field. The weight and the basal shoot numbers were evaluated. The regrowth dynamics after the cut and seasonally of production using three cutting frequencies, 28, 35 and 42 days, and three defoliation intensities, cuts at $7 \mathrm{~cm} \mathrm{height} \mathrm{with} \mathrm{or} \mathrm{without}$ preservation of remaining leaf area and cut at soil level were evaluated. A completely randomized experimental design in a $3 \times 3 \times 2$ factorial arrangement (cultivar, cut frequency and defoliation intensity), with three replications, was used. To evaluate the seasonal production, in the three alone frequency, a split plot experimental design over time was used, in which the whole plot were represented by the treatments (cultivar vs. defoliation intensity) and the split by the cuts. The 28 days cut frequency was the best for both cultivars for dry matter yield of shoots/pot, mainly in the summer time. As for shoot numbers, cut frequencies of 28 and 35 days were superior to 45 days cut frequency. Defoliation intensity of $7 \mathrm{~cm}$, with preservation of the remaining leaf area, was superior to the other, as for weight and shoots numbers. The summer time showed to be favorable to production of these alfalfa cultivars. As for the appearance of regrowth shoots, more than $2 / 3$ of shoots appeared in the two subsequent weeks after the cut, independently of cut frequency and of defoliation intensity. In tropical conditions, there is a possibility to obtain high yields with alfalfa plants since the use of about 28 days of cut intervals has to be observed. In addition, cuts closely to $7 \mathrm{~cm}$ from soil level are favorable, in order to explore the photosynthetic ability of the remaining leaf area and of the regrowth shoots present in the moment of cut.
\end{abstract}

Key Words: alfalfa, cultivar Crioula, cultivar CUF-101, cutting management

${ }^{1}$ Prof. Dr. Depto. de Zootecnia - F.C.A. - UNIMAR-Marília, SP.

${ }^{2}$ Prof. Titular Depto. de Zootecnia-ESALQ-USP-Piracicaba, SP.

${ }^{3}$ Pesquisador Cientifico-Instituto de Zootecnia-Nova Odessa, SP 


\section{Introdução}

A alfafa (Medicago sativa, L.) é uma planta forrageira perene, originária do continente asiático, de onde se difundiu para a Europa e as Américas. É considerada a mais antiga e uma das mais estudadas plantas forrageiras de que se tem conhecimento.

Essa distribuição geográfica, ao longo dos anos, originou grande número de cultivares adaptadas às condições locais; neste sentido, foram distribuídas em nove grupamentos, de acordo com seu grau de repouso invernal, as cultivares dormentes, que têm interrupção ou paralisação do crescimento no inverno, e as cultivares não-dormentes, que são as de crescimento ativo no inverno. Estas últimas podem, também, sofrer redução ou atraso no desenvolvimento invernal, em função de condições climáticas, como a menor radiação solar e umidade do solo (COSTA e MONTEIRO, 1997).

No Brasil, foi introduzida provavelmente pela região Sul - Uruguai e Argentina; atualmente, sua área de cultivo está ao redor de 26 mil ha (MICHAUD et al., 1988), com $80 \%$ desse total localizados no Rio Grande do Sul (FIBE, 1989). Por sua ampla distribuição geográfica e excelente qualidade nutricional, o interesse por seu cultivo vem aumentando em nosso país.

No entanto, a persistência da produtividade dos alfafais tem se constituído em desafio aos produtores, visto que, entre as causas para a degradação dos mesmos, estão manutenção do alto nível de fertilidade do solo exigido por esta cultura, manejo de cortes adequado e controle de plantas invasoras, pragas e doenças.

Pesquisas iniciadas por OLIVEIRA (1986) em Piracicaba, SP estabeleceram alguns níveis de produtividade ao redor de $22 \mathrm{t} \mathrm{MS/ha.ano} \mathrm{de} \mathrm{cultivares}$ não-dormentes, como CUF-101 e Florida 77. Por outro lado, a cultivar Crioula tem se destacado como superior às demais no Rio Grande do Sul (NUERNBERG,1986) e em outras regiões do país (COSTA e MONTEIRO, 1997)

Há muito se vêm pesquisando aspectos ligados ao manejo, verificando-se efeitos de diferentes freqüências e alturas de corte sobre a rebrota, em termos de produção e qualidade da forrageira, nas mais variadas condições edafoclimáticas, sendo que os dados da literatura são contraditórios em relação aos efeitos sobre a produção de alfafa.

Segundo LANGER e STEINKE (1965), tanto a altura quanto a freqüência de corte determinam o rendimento subseqüente da planta. Essa rebrota se realiza às expensas das reservas das raízes e da coroa da planta, acumuladas durante o crescimento da mesma. Segundo MONTEIRO (1989), o manejo de cortes rentes ao solo, sem permanência de área foliar remanescente, tem sido um dos motivos determinantes da degradação dos estandes, ao longo do tempo.

BOTREL et al. (1996) afirmaram que cortes freqüentes resultam em baixa produção de forragem, porém de melhor valor nutritivo. Por outro lado, a utilização menos freqüente proporciona produções mais elevadas, porém de baixa qualidade. HODGKINSON et al. (1972) efetuaram desfolhas de intensidades diferentes em plantas da cultivar Hunter River e obtiveram 17,6\% a mais de brotos para as plantas cuja área foliar remanescente foi mantida após o corte.

Em vista dos poucos resultados nas condições edafoclimáticas da região Sudeste do país, este experimento foi realizado com o objetivo de determinar a produção de matéria seca de duas cultivares não-dormentes de alfafa, por intermédio de sua rebrota, submetidas a diferentes freqüências de corte e graus de desfolha.

\section{Material e Métodos}

O experimento foi realizado no Departamento. de Zootecnia da ESALQ, Piracicaba SP, $22^{\circ} 42^{\prime}$ ' 31' ' lat S e $47^{\circ} 38^{\prime}$, 01', long O.

Foram utilizados recipientes de concreto armado, colocados ao ar livre, com altura de $60 \mathrm{~cm} \mathrm{e}$ diâmetro de $40 \mathrm{~cm}$, com volume de $75 \mathrm{~L}$, contendo Terra Roxa Estruturada (Alfissol), que apresentava a seguinte composição química: $\mathrm{P}$ (resina), 9,25 ug/cm $\mathrm{cm}^{3} ; \mathrm{MO}, 3,20 \% ; \mathrm{pH}\left(\mathrm{CaCl}_{2}\right), 6,25 ; \mathrm{K}, 0,22$; $\mathrm{Ca}, 6,85 ; \mathrm{Mg}, 1,13 ; \mathrm{H}+\mathrm{Al}^{3}, 2,37\left(\mathrm{meq} / 100 \mathrm{~cm}^{3}\right)$; CTC, 10,57 e V\% 77,6. O solo destinado ao preenchimento dos vasos foi homogeneamente misturado com os fertilizantes que corresponderam à seguinte adubação por hectare: $35 \mathrm{~kg} \mathrm{P}_{2} \mathrm{O}_{5}, 32 \mathrm{~kg} \mathrm{~K} \mathrm{~K}_{2} \mathrm{O}$ e 0,16 $\mathrm{kg} \mathrm{B}$, nas formas de superfosfato simples e cloreto de potássio e bórax, respectivamente.

O experimento constituiu-se em fatorial $2 \times 3 \times 3$, para o estudo de duas cultivares, três intensidades de corte e três freqüências de corte.

A semeadura das cultivares não-dormentes Crioula e CUF-101 foi realizada no outono, manualmente, com densidade equivalente a $20 \mathrm{~kg} / \mathrm{ha}$ de sementes, inoculadas com Rhizobium mellilotti, em linhas paralelas e profundidade de $2 \mathrm{~cm}$.

Aos 35 dias após a semeadura, fez-se um desbaste, permanecendo 15 plantas por vaso. Foram realiza- 
das adubações de reposição, após cada corte, com 30 $\mathrm{kg} / \mathrm{ha} \mathrm{P}_{2} \mathrm{O}_{5}, 32 \mathrm{~kg} / \mathrm{ha} \mathrm{K}{ }_{2} \mathrm{O}, 0,16 \mathrm{~kg} / \mathrm{ha} \mathrm{B}$ e $1 \mathrm{~kg} / \mathrm{ha} \mathrm{Zn}$, com as mesmas fontes de adubo utilizadas no plantio, mais o sulfato de zinco.

Os cortes das plantas foram feitos manualmente, com tesoura, segundo as três intensidades ou graus de desfolha: 1 . corte a $7 \mathrm{~cm}$ da base, mantendo-se a área foliar abaixo desse nível; 2. corte a $7 \mathrm{~cm}$ da base, retirando-se a área foliar abaixo desse nível, com pequena tesoura de ponta; e 3 . corte rente ao solo $(0 \mathrm{~cm})$. Não foi utilizada a irrigação no experimento.

Foram realizados os cortes às freqüências de 28 , 35 e 42 dias, a partir da uniformização, totalizando 9 , 7 e 6 cortes, respectivamente, durante o período experimental.

Os brotos basilares e aéreos nascidos após o corte foram marcados semanalmente, com pequenos anéis de arame colorido, para identificar o início de seu crescimento. Todos esses brotos foram colhidos separadamente, colocados em estufa para secagem a $65^{\circ} \mathrm{C}$ e pesados, possibilitando identificar a contribuição, em peso seco, dos brotos que nasceram nas diferentes semanas após o corte. Após a pesagem dos brotos separadamente, os valores foram somados para obtenção do peso total dentro de cada freqüência ( 28,35 e 42 dias).

Adotaram-se dois delineamentos experimentais: para comparação do efeito de freqüência de corte e graus de desfolha nos dois cultivares sobre peso e número de brotos, utilizou-se delineamento inteiramente casualizado com três repetições. Para avaliação da produção estacional ao longo do tempo, dentro de cada freqüência, utilizaram-se parcelas subdivididas no tempo, em que as parcelas foram representadas pelos tratamentos e as subparcelas, pelos cortes. Utilizou-se o teste Tukey a 5\% de probabilidade para comparação entre médias. Como o peso dos brotos aéreos foi muito pequeno, as análises estatísticas foram realizadas apenas sobre os brotos basilares.

\section{Resultados e Discussão}

Na Tabela 1 são apresentados os dados referentes ao peso médio dos brotos basilares, em função das freqüências de corte, e na Tabela 2, os resultados referentes aos graus de desfolha das cultivares Crioula e CUF-101 (média de 36 semanas). A análise de variância não mostrou interação significativa entre freqüências de corte e graus de desfolha sobre o peso dos brotos das cultivares estudadas.

Observa-se que o intervalo de 28 dias entre
Tabela 1 - Peso (g MS/vaso) de brotos basilares das cultivares de plantas de alfafa submetidas a três freqüências de corte (média de 36 semanas)

Table 1 - Basal shoots weight (g DM/pot) from Crioula and CUF101 alfalfa cultivars submited to three cutting frequencies (mean of 36 weeks)

Freqüência de corte (dia)

Cutting frequency (day)

\begin{tabular}{|c|c|c|c|}
\hline \multirow[b]{2}{*}{ Cultivar } & & & \\
\hline & 28 & 35 & 42 \\
\hline Crioula & $10,40 \mathrm{aB}^{1}$ & $9,76 \mathrm{aA}$ & $8,62 \mathrm{bB}$ \\
\hline CUF-101 & $12,47 \mathrm{aA}$ & $10,24 \mathrm{bA}$ & $9,72 \mathrm{bA}$ \\
\hline
\end{tabular}

${ }^{1}$ Médias, na coluna (minúscula) e na linha (maiúscula), seguidas de letras diferentes, são diferentes pelo teste de Tukey $(P<0,05)$

${ }^{1}$ Means, within a column (small) and within a row (capital), followed by different letters, are different by Tukey test $(P<.05)$

cortes foi o que resultou na mais alta produção de matéria seca para a cultivar CUF-101 e que os cortes aos 35 e 42 dias não diferiram entre si para esta cultivar. Para a cv. Crioula, as produções obtidas com 28 e 35 dias foram semelhantes e superiores $(\mathrm{P}<0,05)$ ao corte a cada 42 dias. A cv. CUF-101 apresentou peso de brotações superior $(\mathrm{P}<0,05)$ à cv. Crioula nas freqüências de 28 e 42 dias; porém, aos 35 dias a diferença, não foi significativa.

Grande parte das informações encontradas na literatura indica que maiores produções em alfafa são obtidas com cortes a intervalos maiores que 30 dias, em experimentos em vasos ou em parcelas a campo, com cultivares de dormência invernal (OSSOM et al., 1982, SLARKE e MASON, 1987).

BOTREL et al. (1996), trabalhando com a cultivar Crioula na Zona da Mata de Minas Gerais, obtiveram as maiores $(\mathrm{P}<0,05)$ produções de matéria seca, quando as plantas foram cortadas a cada 28 dias e se encontravam no início do florescimento, no período das águas. As menores produções foram obtidas com os cortes a intervalos de 21, 42 e 49 dias.

Acreditava-se que, por intermédio da freqüência de cortes de 28 dias, poder-se-ia obter colheitas no estádio vegetativo ou no início do florescimento (SLARKE e MASON, 1987; BOTREL et al.,1996) das cultivares estudadas, o que foi confirmado. No maior intervalo de corte estudado (42 dias) as plantas apresentaram $50 \%$ de florescimento ou mais. A altura de $20 \mathrm{~cm}$ foi atingida aproximadamente aos 15 dias após o corte, principalmente a partir de setembro, quando o ritmo de crescimento das plantas aumentou em virtude das condições climáticas favoráveis de umidade, temperatura e insolação. HODGKINSON (1969) demonstrou que temperatura e fotoperíodo são fatores climáticos responsáveis por diferenças significativas na produtividade da alfafa. Essa observação 
MONTEIRO et al.

Tabela 2 - Peso (g MS/vaso) de brotos basilares de duas cultivares de alfafa submetidas a três intensidades de desfolha (média de 36 semanas)

Table 2 - Basal shoots weight (g DM/pot) from two alfafa cultivars submitted to three defoliation intensities (36 weeks mean) Intensidade de desfolhação

Defoliation intensity

\begin{tabular}{lccc} 
Cultivar & Corte a $7 \mathrm{~cm}$, com preservação & Corte a $7 \mathrm{~cm}$, sem preservação & Corte rente ao solo \\
& da área foliar & da área foliar & Cut from the soil \\
& Cut at $7 \mathrm{~cm}$ height & Cut at $7 \mathrm{~cm}$ height & \\
\hline with preservation of leaf area & without preservation of leaf area & \\
CUF-101 & $10,66 \mathrm{aB}$ & $9,26 \mathrm{bB}$ & $8,85 \mathrm{bA}$ \\
\hline
\end{tabular}

${ }^{1}$ Médias, na coluna (minúscula) e na linha (maiúscula), seguidas de letras diferentes, são diferentes pelo teste de Tukey $(P<0,05)$

${ }^{1}$ Means, within a column (small) and within a row (capital), followed by different letters, are different by Tukey test $(P<.05)$.

foi suportada por MARTEN (1970), que obteve adiantamento da maturidade das plantas, quando as temperaturas passaram de 13 para $24^{\circ} \mathrm{C}$. No presente trabalho, os valores médios de temperatura dos períodos entre cortes efetuados a partir de setembro/outubro alcançaram $23^{\circ}$ a $26^{\circ} \mathrm{C}$, o que poderia explicar a maior velocidade de maturação das plantas estudadas sob as condições climáticas de Piracicaba. Assim, acreditase que ao redor de 28 dias a planta já tenha atingido os mais elevados níveis de produção, como demonstra a Tabela 1. Esse fato indica que, sob condições tropicais, é provável que a freqüência de corte seja de, aproximadamente, 28 dias, a campo.

Pela análise dos dados do presente experimento, pode-se observar a diminuição no peso de brotos em 17 e $23 \%$, quando se compararam os resultados para os cortes realizados na freqüência de 28 e 42 dias para as cultivares Crioula e CUF-101, respectivamente. Estes valores indicam que as cultivares reagiram diferentemente ao atraso no corte, sugerindo que a cv. CUF-101 talvez seja mais sensível que a cv. Crioula, aos cortes tardios.

As plantas submetidas aos cortes aos 42 dias tiveram amarelecimento e perda de folhas, havendo, inclusive, dobramento das hastes mais velhas sobre a base da touceira, principalmente na cultivar Crioula.

LEACH (1969) obteve decréscimo uniforme no peso de brotos e raízes de quatro cultivares de alfafa, quando, três dias antes do corte, as plantas foram sombreadas, notando ainda diferença significativa entre as cultivares, quando submetidas a esse tratamento. Isso indica que o sombreamento observado visualmente na base da touceira com o corte tardio, talvez, possa ter contribuído para determinar a diferença observada no comportamento das cultivares.

LOWE et al.(1985) já demonstraram que a cultivar CUF-101 apresenta 10\% de superioridade em relação ao peso de brotos quando comparada às cvs.
Condura 73, Pioneer 581, Hunter River, DK 183 e Matador, que apresentaram diferentes níveis de dormência. Os resultados do presente experimento, bem como o de OLIVEIRA (1986), conduzido sob condições climáticas semelhantes, indicam que a cv. CUF-101 tem características produtivas que podem ser exploradas sob condições de Brasil Central.

A Tabela 2 apresenta o peso dos brotos basilares das duas cultivares estudadas submetidas aos três graus de desfolha. A cultivar CUF-101 apresentou brotos mais pesados que a cultivar Crioula, quando ambas foram submetidas a cortes a $7 \mathrm{~cm}$, com ou sem remoção de área foliar remanescente, mas que os brotos basilares de ambas as cultivares se mostraram mais pesados sob corte a $7 \mathrm{~cm}$ com preservação da área foliar.

ZIMMER et al. (1982) obtiveram no Rio Grande do Sul com a cv. Crioula maiores produções, quando as plantas foram colhidas a $4 \mathrm{~cm}$ que a $8 \mathrm{~cm}$ de altura. Por outro lado, JACQUES et al. (1974) verificaram maiores produções de matéria seca, em casa de vegetação, com cortes a $7,5 \mathrm{~cm}$ que a $2,5 \mathrm{~cm}$ de altura. A diferença nos valores de produção de matéria seca diminuiu entre as alturas de corte estudadas, quando as plantas se encontravam em estádios mais avançados de desenvolvimento. JACQUES (1976), em condições de campo, não encontrou diferença entre cortes a 4 e $8 \mathrm{~cm}$ acima da coroa. No presente trabalho, testaram-se diferentes intensidades de corte por meio da retirada de brotos aéreos, ao invés da altura de corte, embora se possa concluir, por intermédio dos dados da Tabela 2, que os resultados foram concordantes com JACQUES et al. (1974) e JACQUES et al.(1982). Estes dados revelam maiores produções, em peso de brotos de ambas as cultivares, para o corte a $7 \mathrm{~cm}$ da coroa. $\mathrm{O}$ corte realizado rente ao solo mostrou-se desfavorável, indicando a importância de presença da área foliar remanescente após o corte para acelerar o ritmo de 
crescimento da nova rebrota. Igualmente, sob cortes a $7 \mathrm{~cm}$, com ou sem preservação da área foliar remanescente, a cv. CUF-101 apresentou superioridade significativa sobre a cv. Crioula com relação ao peso de brotos por vaso, porém, quando foram submetidos ao corte mais severo, não se observaram diferenças entre essas duas cultivares de alfafa. Estes resultados sugerem que a cv. CUF-101 tem maior potencial de produção que a cv. Crioula, se suas exigências fisiológicas forem atendidas quanto à freqüência e severidade de corte.

Os brotos aéreos tiveram pouca importância como componentes da produção, com peso médio de, aproximadamente, $0,2 \mathrm{~g}$ por vaso, comprovando que os brotos basilares são determinantes da mesma. LEACH (1970), estudando origem dos brotos após o corte, em alfafais, constatou que $90 \%$ da produção de matéria seca podem ser atribuídos a brotos que iniciaram crescimento na coroa ou até $2 \mathrm{~cm}$ acima.

A Tabela 3 mostra a distribuição estacional do peso seco dos brotos basilares (g MS/vaso) para a freqüência de corte 28 dias. Os resultados deste experimento indicam que, a partir de outubro, as cultivares de alfafa estudadas mostraram aumento da produção de MS. Estes resultados são concordantes com PASSOS (1994), o qual relatou que as temperaturas entre 20 e $30^{\circ} \mathrm{C}$ as mais favoráveis para $\mathrm{o}$ crescimento na primeira semana após o corte e entre 30 e $33^{\circ} \mathrm{C}$ para a produção de matéria seca subseqüen- te, por intensificarem os processos fotossintéticos.

Observou-se que a cv. CUF-101 teve acréscimo de 37,6 g MS/vaso contra $29 \mathrm{~g} \mathrm{MS/vaso} \mathrm{da} \mathrm{cv.} \mathrm{Crioula}$ do $4^{\circ}$ para o $5^{\circ}$ corte do período (Tabela 3 ), enquanto o número de brotos se manteve inalterado para as duas cultivares, neste mesmo período (Tabela 4). Este fato pode ser explicado, provavelmente, pela maior adaptação da cv. CUF-101 a temperaturas mais altas que a Crioula, selecionada no Sul do Brasil, onde as temperaturas são mais baixas que na região Sudeste.

A temperatura mais elevada influenciou o crescimento das plantas, por meio do aumento da área foliar do broto basilar, como identificou LEACH (1971). Esse autor determinou que a planta respondeu com aumento de $22 \%$ da área foliar dos brotos basilares, quando a temperatura aumentou de 15 para $27^{\circ} \mathrm{C}$. Os pesos dos brotos, entretanto, elevaram-se quando a temperatura variou de 15 a $21^{\circ} \mathrm{C}$, demonstrando a importância das variações ambientais sobre a produtividade da planta. Esse fato poderia explicar os resultados apresentados na Tabela 3, os quais indicam que as plantas cortadas a $7 \mathrm{~cm}$, com preservação da área foliar, tiveram maiores acréscimos no peso de brotos, quando submetidas aos cortes de novembro.

Durante o período de inverno, as plantas não responderam aos diferentes graus de desfolha, entre os meses de julho e outubro (Tabela 3). Com o aumento da área foliar, juntamente ao aumento da temperatura, além do incremento na porcentagem de

Tabela 3 - Peso seco (g MS/vaso) de brotos basilares da alfafa, cultivares Crioula e CUF-101, cortadas a diferentes intencidade de desfolha sob a frequência de corte 28 dias (médias mensais)

Table 3 - Basal shoot weight (g DM/pot) from alfalfa plants, cultivars Crioula e CUF-101, and submitted to different levels of defoliation intencity under cut frequency of 28 days (month mean)

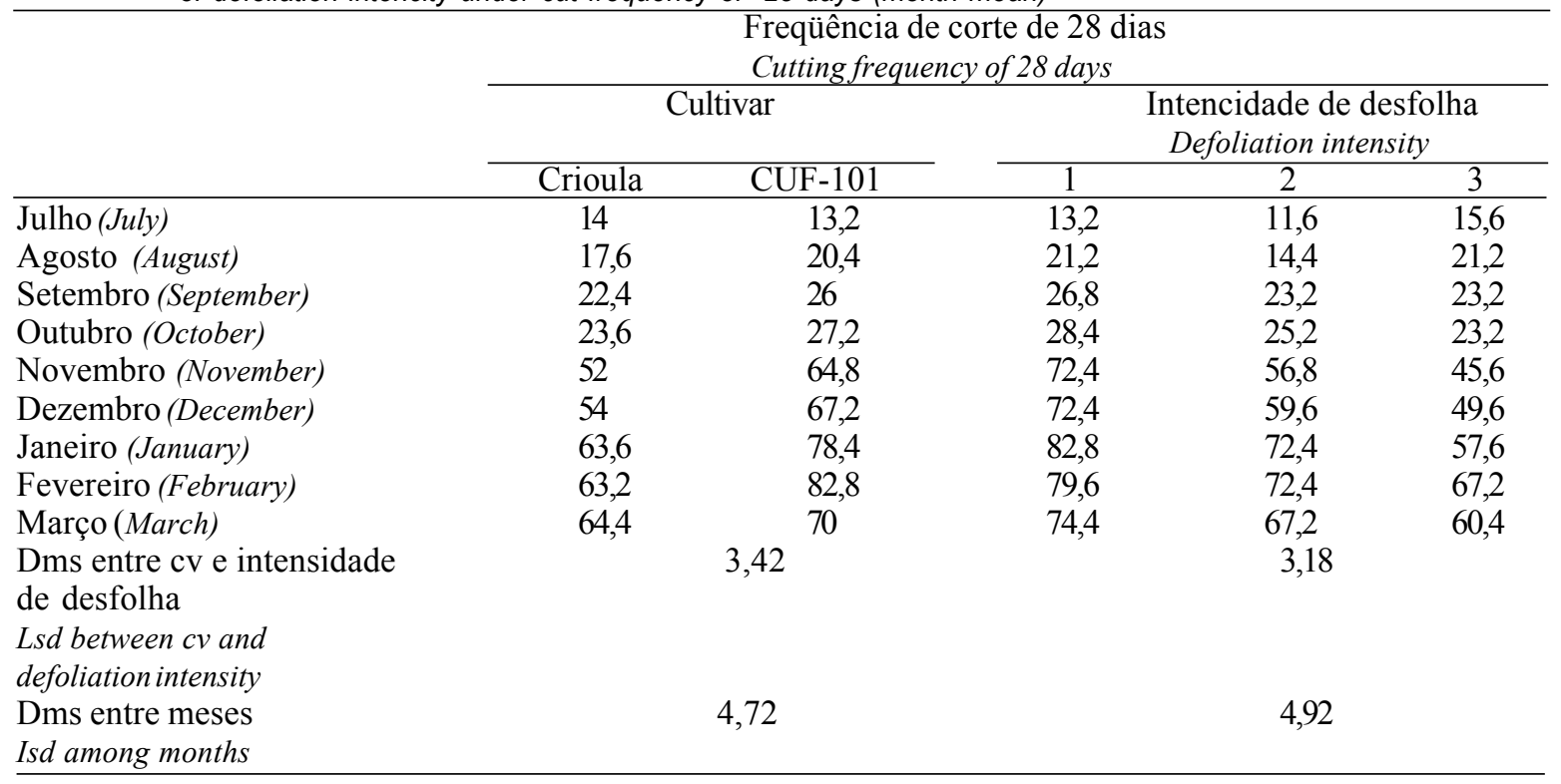


folhas e na capacidade fotossintética das folhas remanescentes nos brotos basilares, após o corte, as plantas quando submetidas à desfolha leve, provavelmente, estavam mais preparadas para responder, com crescimento e produção, às condições ambientais.

A Tabela 4 mostra o número de brotações basilares das cultivares Crioula e CUF-101 submetidas à freqüência de corte 28 dias e aos graus de desfolha, no período de julho a março. As duas cultivares também apresentaram aumento no número de brotos basilares nos meses de primavera-verão. Considerando graus de desfolha, na freqüência 28 dias, o corte à altura de $7 \mathrm{~cm}$, com manutenção da área foliar, foi o que apresentou elevação mais acentuada no número de brotos basilares $(\mathrm{P}<0,05)$ em relação às demais intensidades de corte, complementando os resultados já discutidos para a variável peso de brotos.

A Tabela 5 mostra a dinâmica de aparecimento de brotos ao longo do tempo, dentro de cada freqüência de corte e sob os diferentes graus de desfolha para as duas cultivares estudadas. Tornou-se evidente que a rebrota ocorre mais intensamente na primeira semana após o corte, com valores acima de $60 \%$ do número total de brotos em todos os tratamentos. Os resultados obtidos são concordantes com os resultados de LEACH (1969, 1970), o qual verificou que a rebrota da alfafa é determinada pelos brotos nascidos até 10 a 15 dias após o corte e atribuiu extrema importância à área foliar dos brotos basilares para explicar a velocidade do crescimento inicial da rebrota. LEACH (1978) relatou declínio na taxa de crescimento após a primeira semana; assim, os maiores brotos, nascidos logo após o corte, inibem o crescimento dos seguintes.

Tabela 5 - Número de brotos basilares/vaso que surgiram semanalmente em plantas de alfafa (média de duas cvs.) submetidas a três intensidade de desfolha e três freqüências de corte

Table 5 - Number of basal shoots/pot that appeared weekly in alfalfa plants (mean of two cvs) submitted to three defoliation intensity and three cutting frequencies

Freqüência Intensidade Dias após o corte

\begin{tabular}{lccccccc} 
Frequency & Intensity & \multicolumn{6}{c}{ Days after cutting } \\
\cline { 2 - 8 } & & $7^{\mathrm{O}}$ & $14^{\mathrm{O}}$ & $21^{\mathrm{O}}$ & $28^{\mathrm{O}}$ & $35^{\mathrm{O}}$ & $42^{\mathrm{O}}$ \\
\hline \multirow{2}{*}{28 dias $^{1}$} & 1 & 51,2 & 13,6 & 1,3 & 4,9 & - & - \\
& 2 & 43,2 & 11,5 & 2,3 & 4,1 & - & - \\
& 3 & 40,7 & 11,9 & 0,8 & 2,9 & - & - \\
& & & & & & & \\
35 dias & 1 & 61,8 & 17,6 & 3,4 & 2,2 & 3,9 & - \\
& 2 & 64,3 & 15,7 & 3,1 & 2,2 & 3,3 & - \\
& 3 & 59,0 & 15,2 & 3,7 & 2,5 & 5,2 & - \\
42 dias & 1 & 54,3 & 13,3 & 2,2 & 3,6 & 4,3 & 9,8 \\
& 2 & 52,6 & 11,6 & 1,5 & 3,7 & 3,7 & 8,6 \\
& 3 & 39,2 & 10,6 & 0,8 & 2,7 & 3,7 & 8,8 \\
\hline
\end{tabular}

${ }^{1}$ Dias (days).

Tabela 4 -Número de brotos basilares/vaso de alfafa, cultivares Crioula e CUF-101,cortadas a diferentes intensidades de desfolha sob a frequência de corte 28 dias (médias mensais)

Table 4 - Number of shoots/pot from alfafa plants, cultivars Crioula and CUF-101, cut at different defoliation intensity under the cut frequency of 28 days (month mean)

\begin{tabular}{|c|c|c|c|c|c|}
\hline & \multicolumn{5}{|c|}{$\begin{array}{l}\text { Freqüência de corte de } 28 \text { dias } \\
\text { Cutting frequency of } 28 \text { days }\end{array}$} \\
\hline & \multicolumn{2}{|c|}{ Cultivar } & \multicolumn{3}{|c|}{$\begin{array}{l}\text { Intencidade de desfolha } \\
\text { Defoliation intensity }\end{array}$} \\
\hline & Crioula & CUF-101 & 1 & 2 & 3 \\
\hline$\overline{\text { Agosto (August) }}$ & 30,8 & 31,2 & 31,6 & 29,2 & 31,6 \\
\hline Setembro (September) & 32,4 & 32,4 & 34,8 & 30,4 & 32,4 \\
\hline Outubro (October) & 43,6 & 44,8 & 48,8 & 43,2 & 40,4 \\
\hline Novembro (November) & 44,4 & 44,4 & 49,6 & 42,8 & 40,4 \\
\hline Dezembro(December) & 82,4 & 92,4 & 107,2 & 82,4 & 72,8 \\
\hline Janeiro (January) & 94 & 103,2 & 110,8 & 103,6 & 81,2 \\
\hline Fevereiro (February) & 92,4 & 110,8 & 119,2 & 88,8 & 97,2 \\
\hline Março (March) & 93,6 & 112 & 124,8 & 88 & 95,2 \\
\hline $\begin{array}{l}\text { Dms entre cv e intensidade } \\
\text { de desfolha }\end{array}$ & 2,31 & 5,12 & & & \\
\hline \multicolumn{6}{|l|}{$\begin{array}{l}\text { Lsd between } \mathrm{cv} \text { and } \\
\text { defoliation intensity }\end{array}$} \\
\hline Dms entre meses & \multirow{2}{*}{\multicolumn{2}{|c|}{6,23}} & \multirow{2}{*}{\multicolumn{3}{|c|}{6,18}} \\
\hline Isd among months & & & & & \\
\hline
\end{tabular}




\section{Conclusões}

A intensidade e a freqüência de cortes condicionaram o número e o peso dos brotos basilares das cultivares CUF-101 e Crioula, principalmente durante o verão. A cultivar Crioula pode ser cortada a cada 28 a 35 dias e a CUF-101, a cada 28 dias.

\section{Referências Bibliográficas}

BOTREL, M. A., ALVIM, M. J., XAVIER, D. F. 1996. Frequência de corte da alfafa (Medicago sativa) cv. Crioula em Minas Gerais. R. Soc. Bras. Zootec., 25(3):396-403.

COSTA, C., MONTEIRO, A.L.G. Alfafa como forrageira para corte e pastejo. In: SIMPÓSIO SOBRE ECOSSISTEMA DE PASTAGEM, 3, 1997, Jaboticabal. Anais...Jaboticabal: FCAV-UNESP, 1997, p.297-317.

FUNDAÇÃO INSTITUTO BRAS. DE ESTATÍSTICA, 1989. Anuário Estatístico do Brasil, 1989. IBGE.

HODGKINSON, K.C. 1969. The utilization of root organic compounds during the regeneration of lucerne. Austr. J. Biol. Sci., 22(5):1113-1123.

HODGKINSON, K.C., SMITH, N.G., MILES, G.E. 1972. The photossyntetic capacity of stubble leaves and their contribution to growth of the lucerne plant after high level cutting. Austr. J. Agric. Res., 23:225-228.

JACQUES, A.V.A. Consorciação de gramíneas e leguminosas forrageiras. In: SIMPÓSIO SOBRE MANEJO DA PASTAGEM, 2, 1976, Piracicaba. Anais... Piracicaba: FEALQ, 1976, p.191-192.

JACQUES, A.V.A., BARRETO, I.L.,VEIGA,L.F.S. Efeito do estádio de crescimento e da altura de corte sobre a acumulação de matéria seca e crescimento de raízes de alfafa (Medicago sativa L). In: REUNIÃO DA SOCIEDADE BRASILEIRA DE ZOOTECNIA, 11, 1974, Fortaleza. Anais... Fortaleza: SBZ, 1974, p.377-378.

JACQUES, A.V.A., STAMMEL, J.G., RIBOLDI, J. Efeito do estádio de crescimento e altura de corte sobre a matéria seca, proteína bruta e minerais da alfafa Crioula (Medicago sativa) In: REUNIÃO DA SOCIEDADE BRASILEIRA DE ZOOTECNIA, 19, 1982, Piracicaba. Anais... Piracicaba, SBZ, 1982, p.435-436.

LANGER, R.H.M., STEINKE,T.D. 1965. Growth of lucerne in response to height and frequency of defoliation. J. Agric. Sci., 64(2):291-294.

LEACH, G.J. 1969. Shoot numbers, shoot size, and yield of regrowth in three lucerne cultivars. Austr. J. Agric. Res., 20(3):425-435.

LEACH, G.J. 1970. Shoot growth on lucerne plants cut at different heights. Austr. J. Agric. Res., 21(4):583-591.

LEACH, G.J. 1971. The relation between lucerne shoot growth and temperature. Austr. J. Agric. Res. 22(1):49-59.

LEACH, G.J. 1978 The ecology of lucerne pastures. In: WILSON, J.R. (Ed.) Plant relations in pastures. Melbourne: CSIRO, p.290-308.

LOWE, K.F., BROWDLER,T.M., SCHORODTER,G.N. 1985. Effect of cutting height on lucerne (Medicago sativa, L.) cultivars. Trop. Grass., 19(1):24-28.

MARTEN, G.C. 1970. Temperature as a determinant of quality of alfafa harvested by bloom stage or age criteria. In.: INTERNATIONAL GRASSLAND CONGRESS, 12, 1970, Surfers Paradise. Proceedings... Austrália: Univ. Queensland Press, p.506-599.

MICHAUD, R., LEHMAN, W.F., RUMBAUCH, M. D. 1988. World distribution and historical development. In: HANSON, A.A., BARNES, D.K., HILL, R.R. (Eds.) Alfalfa and alfalfa improvement. Madison: American Soc. of Agronomy. p. 25-91.

MONTEIRO, A.L.G. 1989. Avaliação das características morfológicas e fisiológicas de dois cultivares não dormentes de alfafa (CUF 101 e Crioula) através do manejo da área foliar dos perfilhos basilares. Piracicaba, SP: ESALQ-USP, 1989, 116 p. Dissertação (Mestrado) - Escola Superior de Agricultura "Luiz de Queiroz"/Universidade de São Paulo.

NUERNBERG, N.J. Técnicas de produção de alfafa. In: SIMPÓSIO SOBRE MANEJO DA PASTAGEM, 8, 1986, Piracicaba. Anais... Piracicaba: FEALQ, 1986, p.145-160.

OLIVEIRA, P.R.D. Avaliação de produção e da qualidade de cultivares de alfafa (Medicago sativa L.). Piracicaba, SP: ESALQ-USP, 1986, 75p. Dissertação (Mestrado) - Escola Superior de Agricultura "Luiz de Queiroz"/Universidade de São Paulo, 1986.

OSSOM, E.M., RHYKERD, C. L., HOLT, D.A. 1982. Influence of cutting management on nonstructural carbohydrate accumulation and crop survival in Medicago sativa L. In: THE INDIANA ACADEMY OF SCIENCE, 1982, Purdue. Proceedings... Purdue: Apud Herbage Abstracts, 91:213-16. (Resumo).

PASSOS, L. P. 1994. Indicadores fisiológicos para a cultura da alfafa nos trópicos. In: BOTREL, M. A., ALVIM, M. J., PASSOS, L. P., VILELA, D. (Eds.) Workshop sobre potencial forrageiro da alfafa (Medicago sativa $L$ ) nos Trópicos. Juiz de Fora, MG. 224p.

SLARKE, R.H., MASON, W.K. 1987. Effect of growth stage at cutting on yield and quality of lucerne cultivars from different dormancy groups in northern Victoria. Austr. J. Exp. Agric., 27(3):55-58.

SMITH, D., NELSON, C.J. 1967. Growth of birdsfoot trefoil and alfafa. I. Responses to height and frequency of cutting. Crop Sci., 7(2):130-133.

ZIMMER, H., JACQUES, A.V.A., MARKUS, R. 1982. Consorciações de gramíneas forrageiras de estação quente com alfafa Crioula, submetidas a duas alturas de corte. Pesq. Agropec. Bras., 17(9):1349-1359.
Recebido em: 30/04/98

Aceito em: 11/11/98 